\title{
Pulmonary blood flow distribution after banding of pulmonary artery
}

\author{
M Šamánek, B. Fišer, C. Ruth, S. Tůma, and B. Hučín \\ From the Cardiopulmonary Laboratory and Department of Paediatric Surgery, University Hospital Motol, \\ and Faculty of Paediatrics, Charles University, Prague, Czechoslovakia
}

Radioisotope lung scanning was used to investigate the distribution of pulmonary blood flow after banding of the pulmonary artery in children with a left-to-right shunt and pulmonary hypertension. An abnormal distribution of blood flow in the lung on the side of the operation approach was observed in all patients in the first three weeks following surgery. Abnormalities were still observed in $I 7$ of 21 children Io months to more than 8 years after the banding operation. There was no significant relation between the occurrence of these abnormalities and time after surgery. Diminished flow to the zones of the right lung was observed less frequently. The incidence of abnormalities in flow distribution was also high preoperatively. Respiratory complications in infants with large left-to-right shunts were considered to be responsible for most of the abnormal blood flow distributions observed. Radioactive lung scanning was found to be a valuable diagnostic method in the early and late postoperative period in infants and small children. It was more sensitive than the other techniques used in revealing deviation of blood flow from one lung in those cases with shifting of the applied band.

A therapeutic value of banding the pulmonary artery in infants with intractable congestive heart failure from a left-to-right shunt has been suggested by reports of the effects of this operation in cases of ventricular septal defects and other congenital cardiac abnormalities involving pulmonary hypertension and a high pulmonary blood flow (Stark et al., 1969; Somerville et al., 1967). The presumed mechanism of action of pulmonary arterial banding is a reduction in pulmonary arterial blood flow because of the applied artificial resistance to right ventricular flow (Muller and Dammann, 1952). Constriction of the proximal part of the pulmonary artery reduces distal pulmonary arterial pressure and flow, but might also affect the distribution of blood flow to the lungs in a manner similar to that found in stenosis of the pulmonary valve (Dollery et al., 196r ; Samánek et al., 1969). Respiratory pathology is common in infants with large left-to-right shunts. Observations on pulmonary blood flow distribution by lung scanning have been shown to be useful in evaluating abnormalities in regional lung function in young children (Fendel and Feine, 1970), particularly in the presence of obstructive lung disease (Samánek et al., 1971). One effect of banding operations is a reduc-

Received 25 February 1974. tion in these respiratory complications. Abnormal pulmonary function may persist for some time after surgery, and in some cases may even be the result of surgery. In this study radioactive lung scanning has been used to evaluate such abnormalities.

One possible postoperative complication is a shift of the ligature along the pulmonary artery distal to the bifurcation. Such a shift may result in an uneven distribution of the pulmonary resistance and a consequent alteration in regional pulmonary blood flow. Differences between right- and left-sided pulmonary blood flow could result in an increase in the dead space of the lung, with lower perfusion and a higher venous admixture from the contralateral lung with a lower ventilation-perfusion ratio. An attempt has been made to use radioisotope lung scanning to reveal deviations of blood away from one lung caused by slipping of the applied band.

\section{Subjects and methods}

Twenty-one children were studied by lung scintiscanning after banding of the pulmonary artery (Table I). Most of the patients were under I year of age at the time of operation. The older patients had been referred for operation in earlier years, or because anatomical conditions had made corrective surgery unfavourable. The most frequent indication for surgery was ventricular septal defect, isolated (12 children), with persistent 
TABLE I Data on patients and results of studies

\begin{tabular}{|c|c|c|c|c|c|c|c|}
\hline \multirow{4}{*}{$\begin{array}{l}\text { Case } \\
\text { No. }\end{array}$} & \multirow[t]{4}{*}{ Sex } & \multirow[t]{4}{*}{ Diagnosis } & \multirow{4}{*}{$\begin{array}{l}\text { Age at } \\
\text { operation } \\
\text { (mth) }\end{array}$} & \multicolumn{3}{|c|}{ Preoperative catheterization } & \multirow{4}{*}{$\begin{array}{l}\text { Pulm. artery } \\
\text { systolic } \\
\text { pressure } \\
\text { after banding } \\
(\mathrm{mmHg})\end{array}$} \\
\hline & & & & \multirow{2}{*}{$\begin{array}{l}\text { Pulm. artery } \\
\text { pressure }(\mathrm{mm} H \mathrm{Hg})\end{array}$} & Shunts & & \\
\hline & & & & & $L-R$ & $R-L$ & \\
\hline & & & & mean & $\left(\% \dot{Q}_{\mathrm{P}}\right)$ & $\left(\begin{array}{ll}\% & \dot{Q}_{\mathrm{s}}\end{array}\right)$ & \\
\hline
\end{tabular}

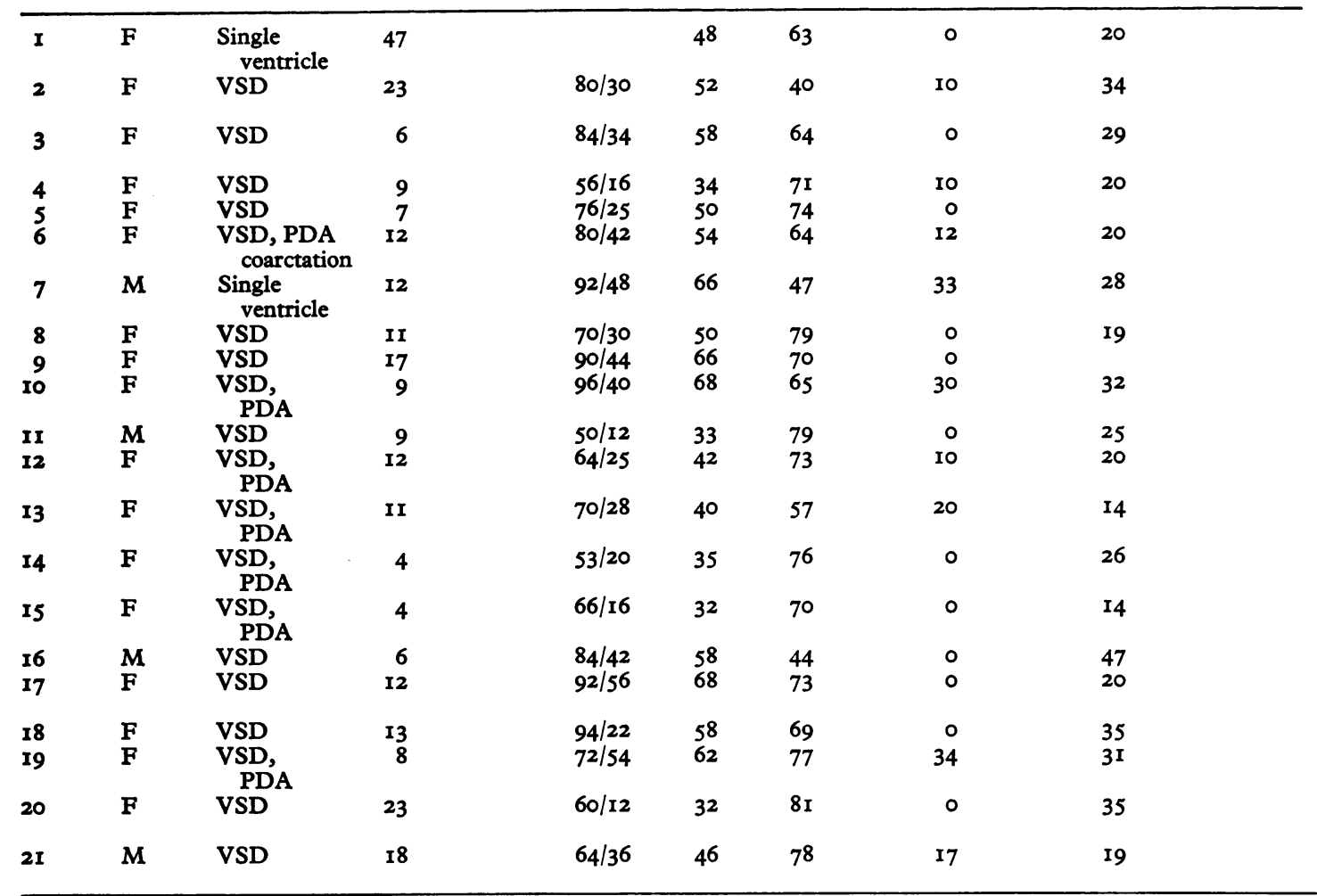

$\mathbf{n}=$ increased pulmonary blood flow without abnormal distribution; $A=$ regional increase of perfusion; $E=$ regional decrease of perfusion. $U$, upper; $M$, middle; $L$, lower zones. Underperfusion degree: $0=$ normal perfusion; $r$ to $3=$ minor to maximal decrease of regional perfusion.

ductus arteriosus (6 cases), or with coarctation of the aorta (I case). The clinical diagnosis was confirmed in all patients by cardiac catheterization. Blood pressures were measured with Statham pressure transducers (P23Db) connected to Accudata II3 (Honeywell) electromanometers. Pressure curves and electrocardiograms were recorded on a Mingograph (Elema-Schönander) direct writing instrument. Oxygen saturation was measured by a micro-oximeter (American Optical Co.). Blood gas tension and acid-base equilibrium were measured from samples withdrawn during cardiac catheterization and during lung scanning. Biplane angiography or cineangiography (Triplex Angiomatic, ElemaSchönander) was carried out before banding in all but 3 of the patients. In 6 cases (Cases $6,10,11,17,19$, and
2I) cardiac catheterization and angiography were repeated postoperatively.

In patients with a ventricular septal defect, the banding operation was carried out through an incision in the left fourth intercostal space. The ductus arteriosus or ligamentum was ligated. The pericardium was then opened and an incision was made between the aorta and the pulmonary artery. Plaited silk (BPC 6) was passed around the pulmonary artery, and the main trunk of the vessel was constricted.

The distribution of pulmonary blood flow was measured by anterior lung scanning with the patients in a supine position. Human serum albumin, aggregated to a particle size of $75 \mu$ and labelled with ${ }^{99 m}$ Tc was administered intravenously in doses from 50 to $200 \mu \mathrm{Ci}$. The 


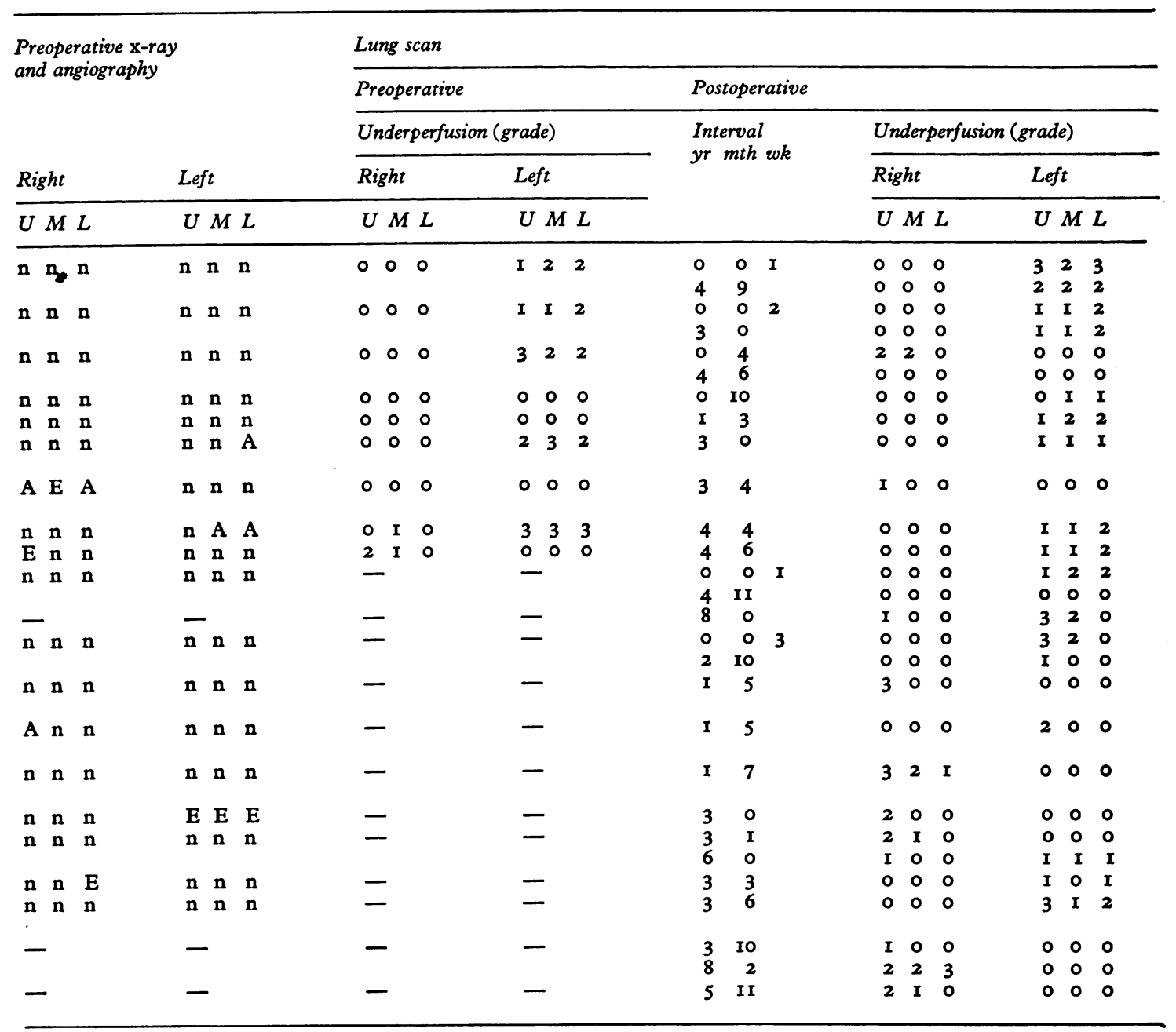

Pho/Dot II. rectilinear scanner (Nuclear Chicago) with a r27-hole collimator was used to record the distribution of the injected radioisotope in the pulmonary arterial circulation. These records were evaluated by dividing each lung into three equal zones. These arbitrary zones did not correspond with the lung lobes. The activity in the three zones was compared by counting points in the scintiscan or by recording counts per second per $\mathrm{cm}^{2}$ in the geometrical centre of each zone (Novak, Frenzel, and Wieners, 1972). Areas of maximal radioactivity were arbitrarily labelled as zero underperfusion; radioactivity equal to background level was defined as grade 3 under perfusion. Grades I and 2 underperfusion lay between these, two extremes.

\section{Results}

Early postoperative scintiscans were obtained in 4 patients $I$ to 3 weeks after operation (Table I, Cases 1, 2, 10, 12). All 4 showed a normal distribution pattern of blood flow to the right lung and an abnormal distribution in the left lung.

Late postoperative scintiscans were recorded in $2 \mathrm{I}$ patients from Io months (Case 4) to more than 8 years after the operation (Table I). Seventeen of these patients showed an abnormal distribution pattern. There was no significant relation between the incidence of abnormal findings and the length 
TABLE 2 Incidence of abnormal distribution of pulmonary blood flow at latest investigation

\begin{tabular}{lll}
\hline $\begin{array}{l}\text { Time after } \\
\text { operation }\end{array}$ & No. of patients & $\begin{array}{l}\text { Percentage of } \\
\text { abnormal findings }\end{array}$ \\
\hline $\begin{array}{l}\text { Io mth to } 3 \text { yr } \\
3 \text { to } 8 \text { yr }\end{array}$ & 6 & $83 \cdot 4$ \\
\hline Total & 21 & $80 \cdot 0$ \\
\hline
\end{tabular}

of time after operation (Table 2). The principal abnormal finding was decreased perfusion of the left lung (Table 3, Fig. I). Diminished flow to the zones of the right lung (Fig. 2) was observed less frequently. The left-to-right difference in perfusion was greatest in the lower zones and least in the upper zones. Localized changes in perfusion were most frequently found in the upper zones. About half of the underperfused areas were classified as grade 1 . Grade 3 changes were met with in only Io per cent of the underperfused areas.

\section{Comparison of preoperative with late post- operative results}

A normal blood flow distribution both preoperatively and postoperatively was seen in only I of 9 patients (Case 7). In 5 cases, an uneven regional distribution of flow was observed both before and after operation. A postoperative improvement in blood flow distribution was encountered in 3 children (Cases 3, 6, 8 - Fig. 4). In one child (Case 2) the operation did not produce any change in the perfusion pattern of the left lung. Postoperative deterioration in blood flow distribution was observed in 4 patients (Cases $1,4,5,9$ - Fig. 5).
Repeated postoperative investigation in 7 patients revealed no change in one (Case 2), improvement of blood flow distribution in 5 children (Cases $1,3,10$, 17, 12 - Fig. 3), and deterioration in Case 20.

Preoperative pulmonary angiograms (Table I) showed a good correlation with the scintiscans in 5 of 9 patients (Cases 4, 5, 6, 9, 8 - Fig. 4). In 3 patients with an abnormal scintiscan (Cases I, 2, 3), they failed to suggest any regional disturbance of perfusion. In one patient (Case 7) the lack of correlation between angiographic and radioisotope scanning results is probably caused by the long time interval between the two investigations. Preoperative pulmonary angiography did not explain the localization of the perfusion abnormalities in any patient with

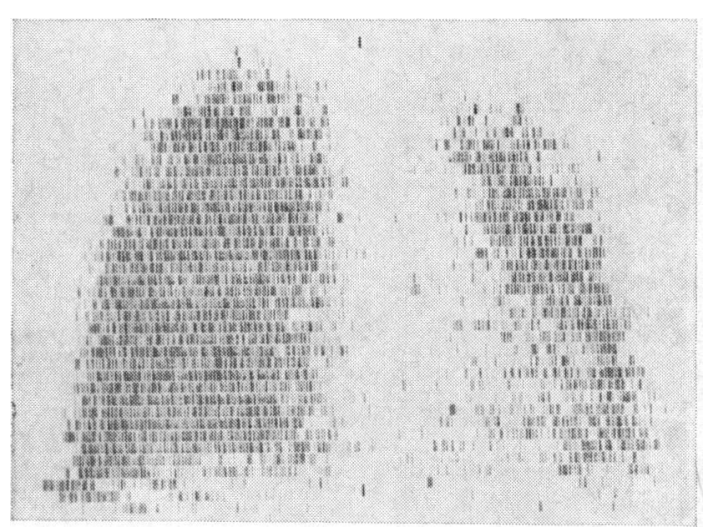

FIG. I (Case 19). Lung scintiscan 3 years and 6 months after banding of the pulmonary artery. Diminished perfusion of the left lung as compared with the right lung.

TABLE 3 Site of underperfusion

\begin{tabular}{lllll}
\hline Region & \multicolumn{2}{l}{ Underperfusion $(\%)$} & Total \\
\cline { 2 - 5 } & Ist grade & 2nd grade & 3rd grade & \\
\hline Right upper & 8 & 10 & 4 & 22 \\
", middle & 4 & 6 & 0 & 10 \\
" lower & 2 & 0 & 2 & 4 \\
\hline Total (right) & 14 & 16 & 6 & 36 \\
\hline Left upper & 16 & 4 & 4 & 24 \\
" middle & 14 & 6 & 0 & 20 \\
" lower & 8 & 12 & 0 & 20 \\
\hline Total (left) & 38 & 22 & 4 & 64 \\
\hline Total & 52 & 28 & 10 & 100 \\
\hline
\end{tabular}


positive abnormal findings postoperatively on radioactive isotope scanning.

Relation of blood flow distribution pattern to position of the ligature could be analysed in 6 patients reinvestigated after the banding (Cases 6, IO, II, I7, I9, 21). In 4 children (Cases IO, II, I7, 2I) the pulmonary artery constriction could be located a short distance from the pulmonary valve (Fig. 6).

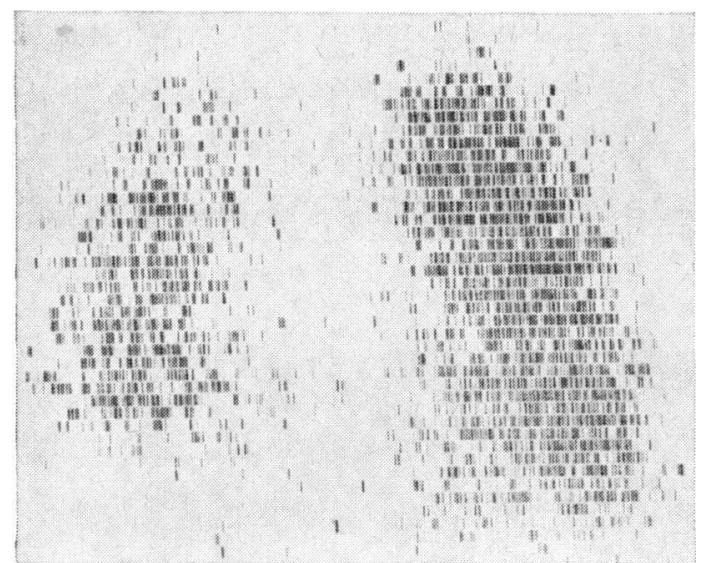

FIG. 2 (Case 20). Lung scintiscan 8 years and 2 months after banding. Right lung is less perfused than the left lung.
Abnormalities in regional distribution of blood flow were recorded in 3 of these (Cases II, 17, 21). In the remaining 2 cases, the ligature had slipped distally towards the bifurcation (Fig. 7). A normal right pulmonary artery pressure with a systolic pressure gradient of $52 \mathrm{mmHg}$ caused by the banding was measured in Case 6. This patient showed only minor differences in the perfusion pattern of both lungs. In Case 19, left lung perfusion was less than on the right side. The systolic gradient across the ligature was $84 \mathrm{mmHg}$, and mean pressure was the same in both pulmonary arteries.

\section{Discussion}

There was a high incidence of abnormal distribution of pulmonary blood flow in these cases both before and after banding. There was also no characteristic pattern of change in this distribution after the operation. The incidence of abnormal patterns was the same before and after operation, and this, together with the lack of any uniform trend after surgery, suggests that the abnormal distributions measured were not the direct result of the banding operation.

Increased flow resistance in isolated pulmonary valvular stenosis has been shown to result in a pre-" ferential distribution of blood flow to the left lung, particularly to the upper lobe (Dollery et al., I96I; Samánek et al., 1969). However, after the banding

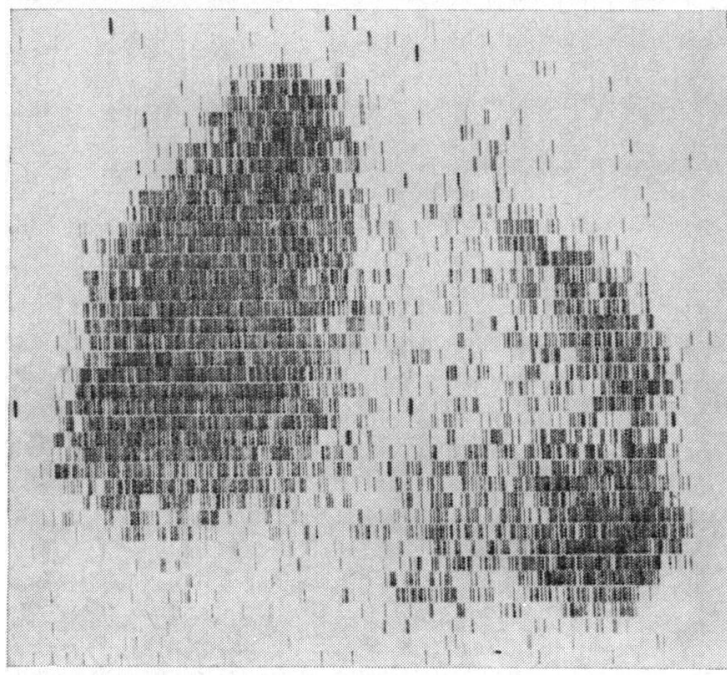

$a$

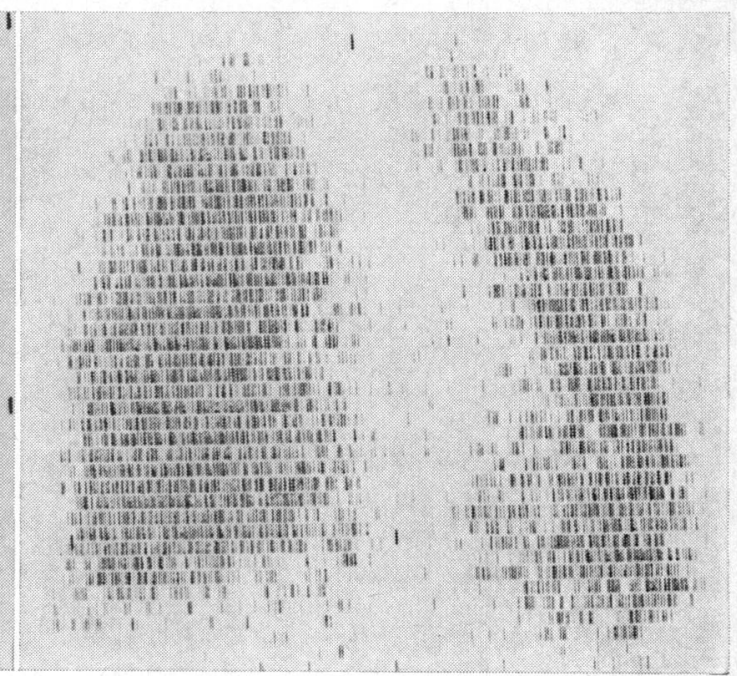

$b$

FIG. 3 (Case I2). (a) Lung scintiscan 3 weeks after the operation. Inequalities in the distribution of pulmonary blood flow, mainly in the left lung. (b) Lung scintiscan 2 years and 10 months after banding. Improvement of the distribution pattern. 


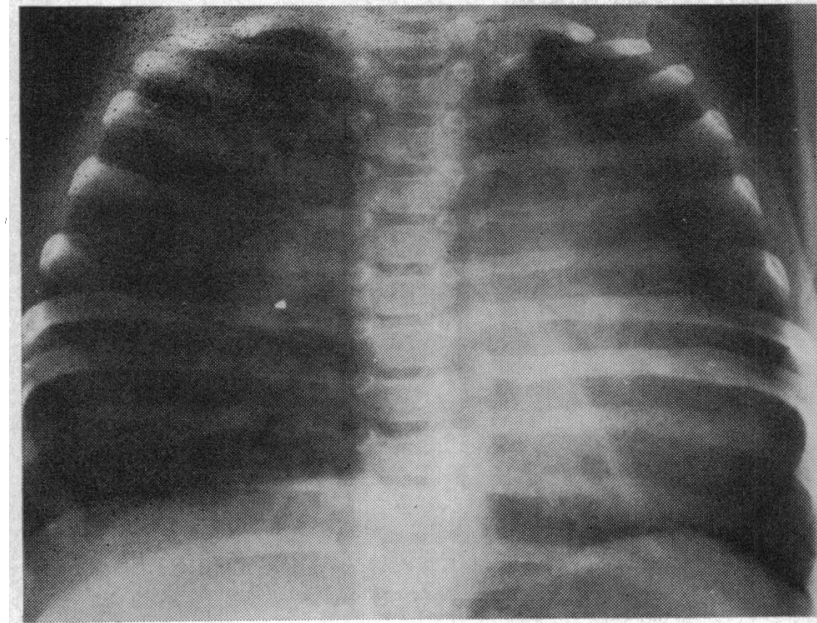

$a$

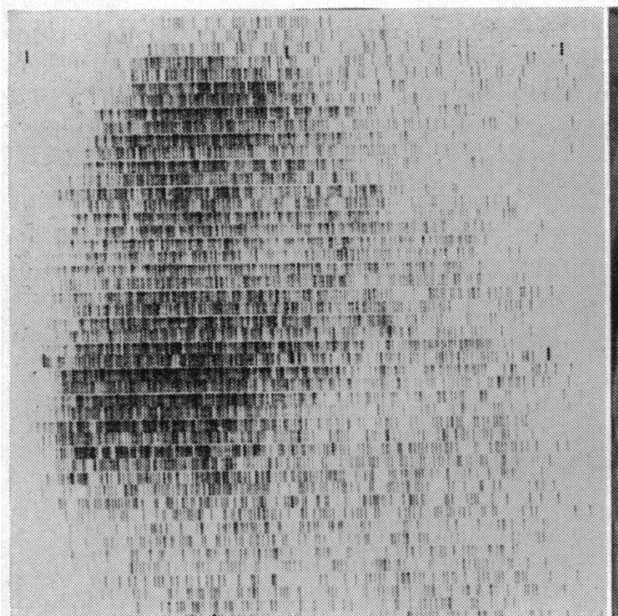

$c$

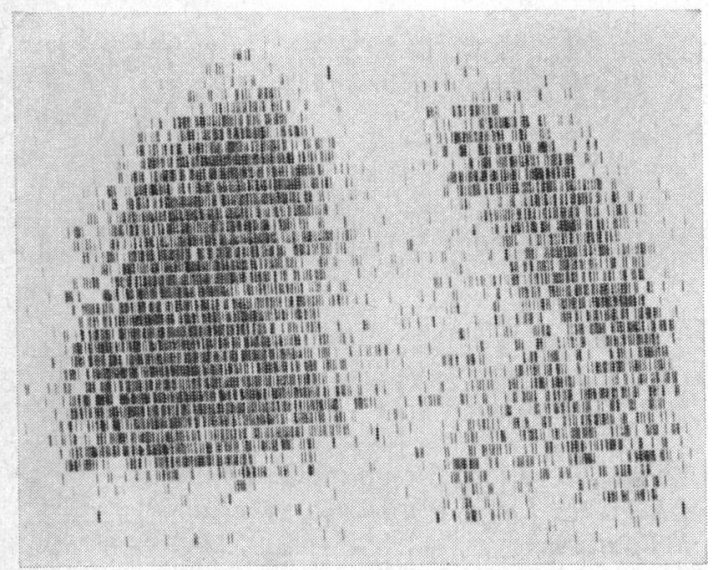

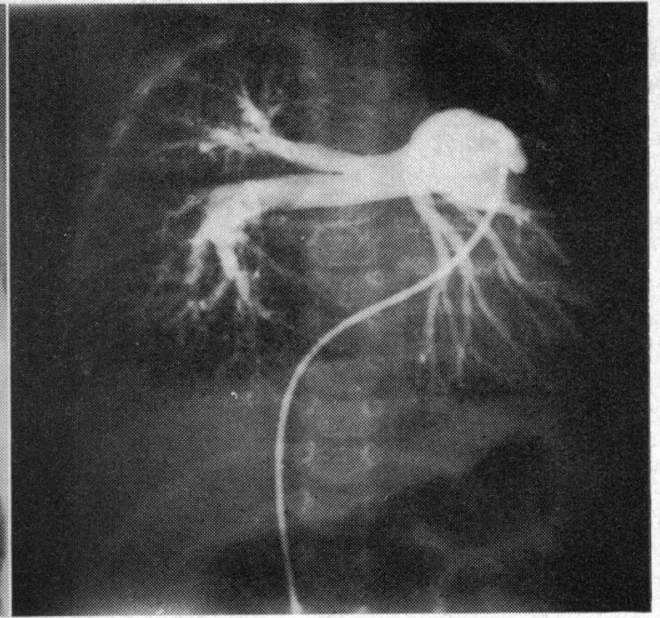

b

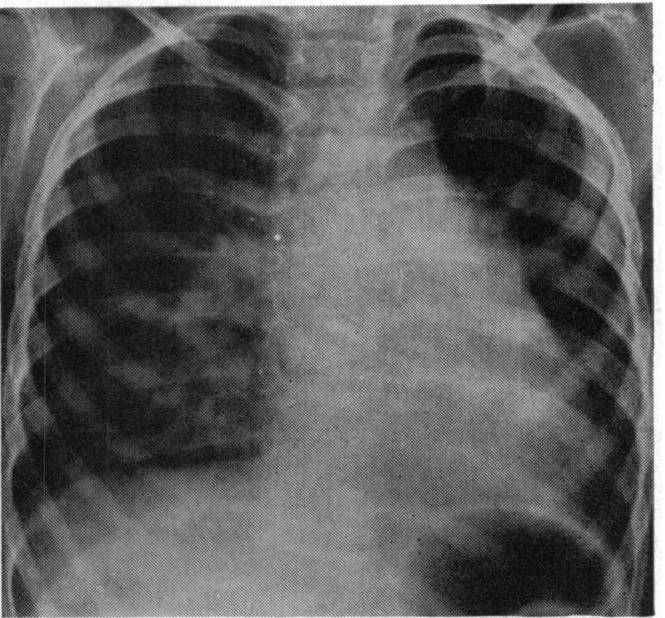

$d$

FIG. 4 (Case 8). (a) Preoperative chest x-ray. Partially collapsed left lung. The heart is shifted to the left. (b) Preoperative pulmonary angiography. Narrowing and downward displacement of the left pulmonary arterial branches. (c) Preoperative lung scintiscan. Abnormal distribution of the pulmonary blood flow between the right and left lung and disturbances of distribution within the right lung. (d) Chest $\mathrm{x}$-ray and (e) lung scintiscan indicate considerable improvement, 4 years and 4 months after the operation, mainly because of the re-expansion of the left lower lobe. 


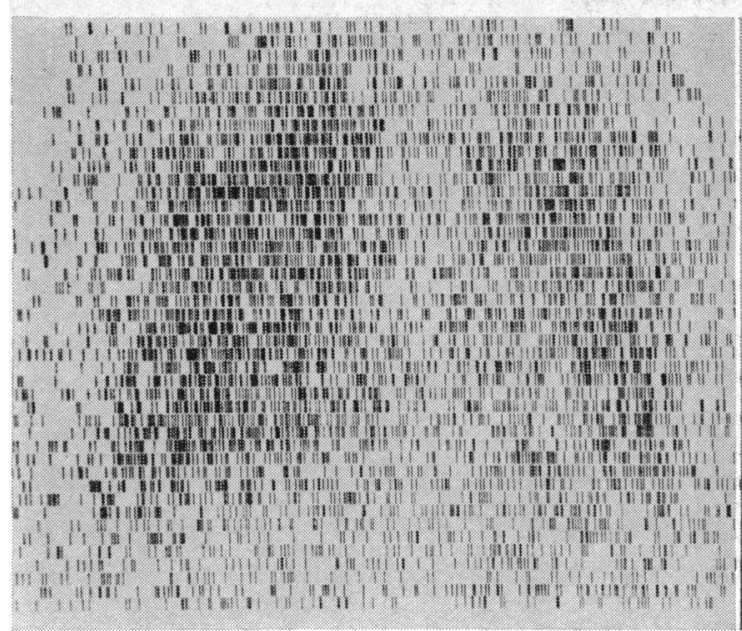

$a$

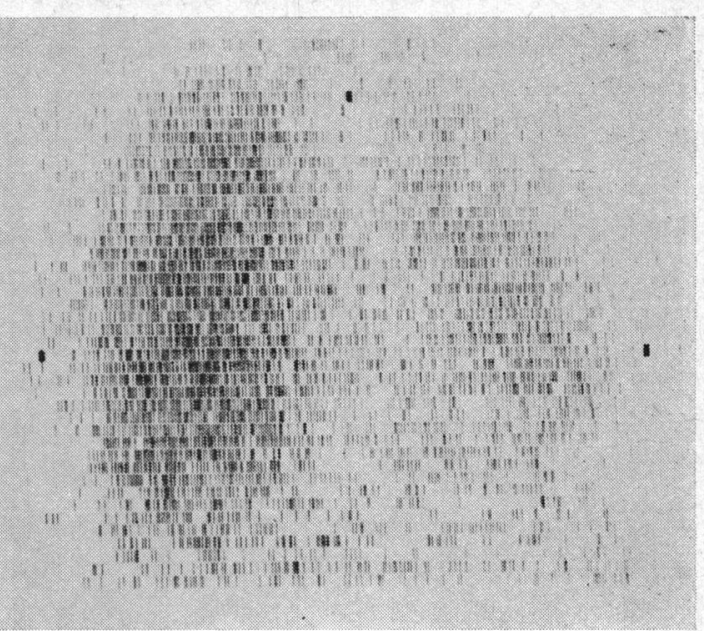

$b$

FIG. 5 (Case I). a) Preoperative scintiscan showing moderate abnormalities of perfusion in the left lung. (b) More pronounced disturbances in perfusion of the left lung on a scintiscan obtained 4 years and 9 months after the banding.

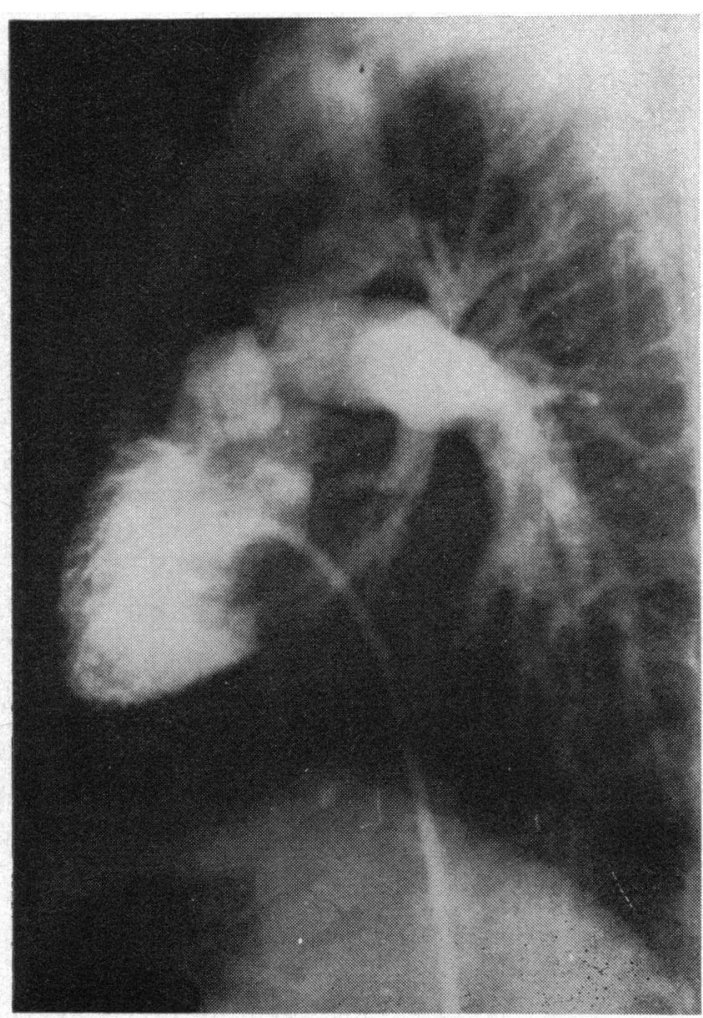

FIG. 6 (Case II). Angiocardiogram showing a typical location of pulmonary arterial narrowing after banding. operation, preferential distribution of blood flow to the left upper zone was seen in only 5 of 21 patients. In other words, we cannot equate the effect of banding to the haemodynamic sequelae of valvular stenosis.

Slipping of the band can result in a greater resistance to flow on one side, and thus alter the ratio of right to left pulmonary blood flows. In such cases, angiography usually fails to locate the site of the narrowing, particularly at the origin of the left pulmonary artery (Fig. 7). Radioisotope lung scanning has been shown to be sufficiently sensitive to reveal asymmetry in blood flow distribution which results from distal slipping of the applied ligature. In 2 of the patients who were recatheterized distal slipping of the band could be demonstrated by angiography. In one of the latter radioisotope lung scanning excluded an asymmetrical constriction of the pulmonary artery. In the second patient radioisotope scanning showed pronounced underperfusion of the left lung despite a lack of evidence of asymmetry on angiography.

Bryant et al. (1967) have shown that thoracotomy per se can result in a transient abnormality in the distribution of pulmonary blood flow in almost half of a series of adult patients. In the present study, an abnormal distribution of blood flow on the left side was found in all cases after operation, and in most of the patients this abnormality persisted for some time. Since thoracotomy produced only transient abnormalities of blood flow distribution in infants and children with tetralogy of Fallot (Samánek 

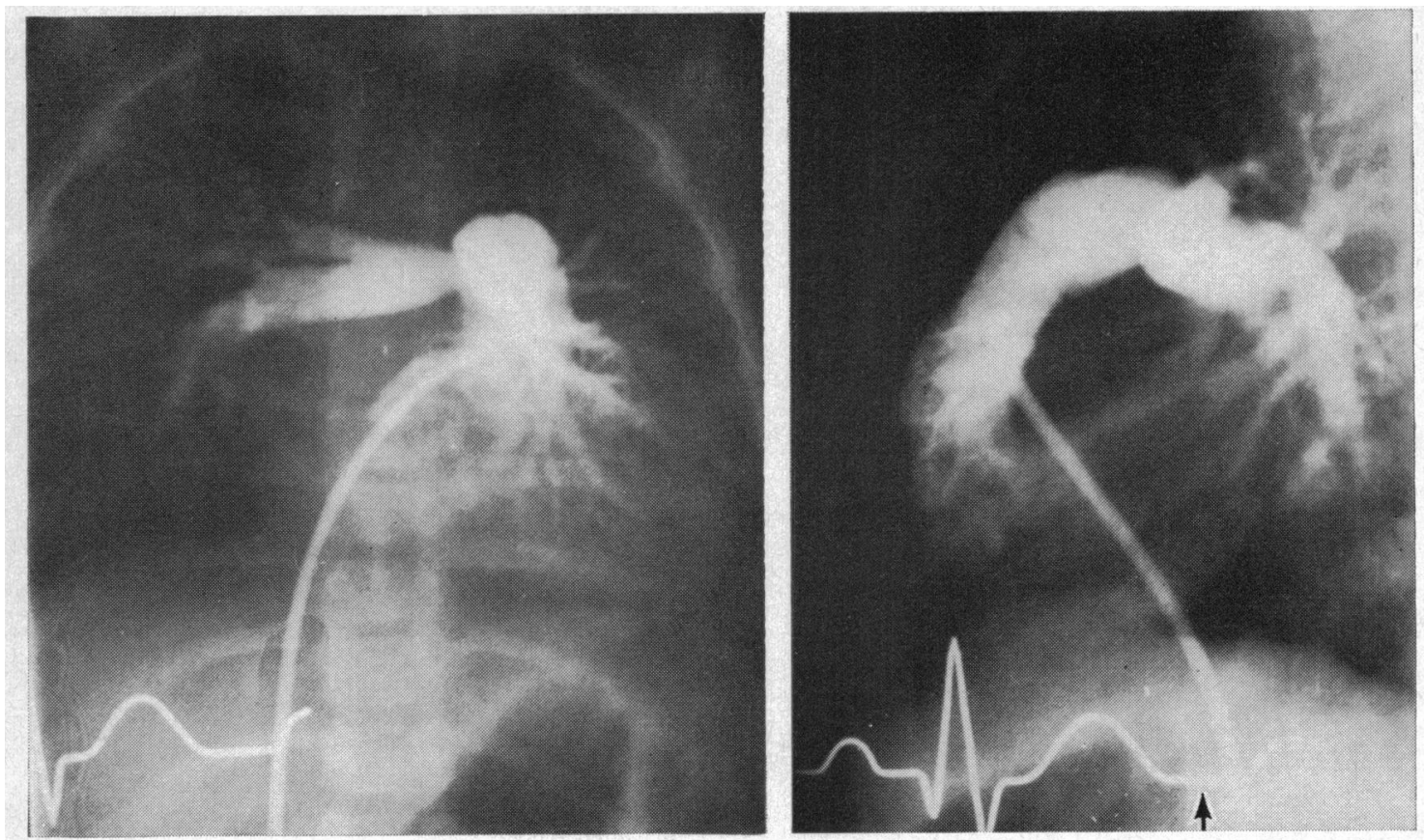

FIG. 7 (Case 6). Postoperative angiogram, anteroposterior and lateral view showing a constriction of the right pulmonary artery at its origin by a slipped band

et al., 1969; Fišer et al., 1974), an explanation of the persistent disturbances in blood flow distribution in congenital heart disease with a left-to-right shunt must be searched for in a difference of pulmonary hemodynamics between these two groups of patients and in disturbances of lung mechanics in infants with a left-to-right shunt and pulmonary hypertension.

Respiratory diseases are probably the most frequent cause of regional disturbances in pulmonary blood flow in infants with large ventricular septal defects. Lung damage develops early in infancy and is caused by several mechanisms. The high pulmonary blood flow and pressure are accompanied by a decrease in pulmonary compliance. Increased bronchial secretion, repeated respiratory infection, and in some cases bronchial compression lead to a disturbance in airway patency and alveolar aeration. It is difficult to test lung function and lung mechanics in infants and small children, such as the present series of patients. Radioisotope lung scanning, however, can be used in this age group to detect regional disturbances in perfusion and impairment of ventilation (Šamánek, 1973). Changes in the composition of alveolar gases which result from alveolar hypoventilation caused by a decrease in regional airway conductance, compression, or a change in lung elasticity are reflected in a decrease in perfusion to the affected region. The same perfusion changes can result from an increase in arterial resistance caused by an increase in alveolar pressure in partial airway obstruction, or by compression of lung tissue in the presence of cardiac hypertrophy.

The patients were clinically improved after banding and showed an incidence of respiratory infection which did not differ from that in a healthy population of the same age. However, an abnormal distribution of blood flow to the lungs, detectable only by lung scintiscanning, persisted (Table 2), suggesting that in most cases the operation did not abolish regional abnormalities of gas exchange. A pronounced improvement in blood flow distribution after banding was encountered only after reexpansion of collapsed regions and consequent elimination of those factors that produced increases in regional resistance to blood flow. Corrective surgery has been reported to improve blood flow distribution in ventricular septal defect (Tong et al., 1973), but patients undergoing banding at an earlier age have not been studied. 


\section{References}

Bryant, L. R., Spencer, F. C., Greenlaw, R. H., Prathnadi, P., and Bowlin, J. W. (1967). Postoperative changes in regional pulmonary blood flow. Fournal of Thoracic and Cardiovascular Surgery, 53, 64.

Dollery, C. T., West, J. B., Wilcken, D. E. L., and HughJones, P. (I96I). A comparison of the pulmonary blood flow between left and right lungs in normal subjects and patients with congenital heart disease. Circulation, 24, 617.

Fendel, H., and Feine, U. (1970). Lungenscintigraphie im Säuglings- und Kindesalter. Monatsschrift für Kinderheilkunde, r18, 601.

Fišer, B., Samánek, M., Ruth, C., Tůma, S., and Hučín, B. (1974). Distribution of the pulmonary blood flow following Waterston's anastomosis. (English summary.) Rozhledy $v$ Chirurgii. In the press.

Muller, W. H., Jr., and Dammann, J. F., Jr. (1952). The treatment of certain congenital malformations of the heart by the creation of pulmonic stenosis to reduce pulmonary hypertension and excessive pulmonary blood flow. Surgery, Gynecology and Obstetrics, 95, 213.

Novak, D., Frenzel, H., and Wieners, H. (1972). Angiography and scintiscanning in preoperative assessment of congenital and acquired lung diseases. In Angiography/ Scintigraphy, p. 174. Ed. by L. Dithelm. Springer, Berlin. Samánek, M. (1973). Indications for the regional lung func- tion studies using radioisotope techniques. In Investigation of the Regional Lung Function, p. 134. Ed. by M. Samánek. Czechoslovak Society of Clinical Physiology of Respiration, Karlovy Vary.

Šamánek, M., Houštěk, J., Vávrová, V., Ruth, C., and Šnobl, O. (I97I). Distribution of pulmonary blood flow in children with cystic fibrosis. Acta Paediatrica Scandinavica, 60, 149.

Samánek, M., Vořišková, M., Goetzová, J., and Tủma, S. (1969). Local pulmonary blood flow in children with stenosis of pulmonary artery. Cardiologia, 54, 235.

Somerville, J., Agnew, T., Stark, J., Waterston, D. J., Aberdeen, E., Bonham-Carter, R. E., and Waich, S. (1967). Banding of the pulmonary artery for common atrioventricular canal. British Heart fournal, 29, 816.

Stark, J., Aberdeen, E., Waterston, D. J., Bonham-Carter, R. E., and Tynan, M. (1969). Pulmonary artery constriction (banding): a report of 146 cases. Surgery, 65, 808.

Tong, E. C. K., Liu, L., Potter, R. T., Sackler, J. P., and Rabinowitz, J. G. (1973). Macroaggregated RISA lung scan in congenital heart disease. Radiology, 106, 585.

Requests for reprints to Dr. M. Samánek, Cardiopulmonary Laboratory, University Hospital Motol, 15006 Prague, Czechoslovakia. 